\title{
Climate Change and Building Energy Consumption: A Review of the Impact of Weather Parameters Influenced by Climate Change on Household Heating and Cooling Demands of Buildings
}

\author{
By Hassan Bazazzadeh ${ }^{1}$, Adam Nadolny ${ }^{2}$, Seyedeh Sara Hashemi Safaei ${ }^{3}$
}

\begin{abstract}
The growth of urban population as the result of economic and industrial development has changed our place of living from a prosperous place to where the resources are carelessly consumed. On the other hand, long-term climate change, i.e. global warming, has had adverse impact on our resources. Certain resources are on the verge of depletion as the consequence of climate change and inconsiderate consumption of resources, unless serious measures are implemented immediately. The building sector, whose share in the municipal energy consumption is considerably high, is a key player that may successfully solve the problem. This paper aims to study the effects of climate change on the energy consumption of buildings and analyze its magnitude to increase the awareness of how construction can reduce the overall global energy consumption. A descriptive-analytical method has been applied to analyze valid models of energy consumption according to different scenarios and to interpret the conditions underlying current and future energy consumption of buildings. The results clearly show that the energy consumption in the building sector increasingly depends on the cooling demand. With that being said, we can expect the reduction of overall energy consumption of buildings in regions with high heating demands, whereas rising the energy consumption in buildings is expected in regions with high cooling demand. To conclude, the long-term climate change (e.g. global warming) underlies the increased energy consumption for the cooling demand whose share in total energy consumption of buildings much outweighs the heating demand. Therefore, to conserve our resources, urban energy planning and management should focus on working up a proper framework of guidelines on how to mitigate the cooling loads in the energy consumption patterns of buildings.
\end{abstract}

Keywords: Climate change; global warming; energy consumption of buildings

\section{Introduction}

Although it is a widely accepted thesis that changes in the climate can have serious impacts on the energy demand, the majority of studies tend to focus on how the energy sector brings about the climate change. In response, a growing number of studies have started to evaluate the reverse impact of climate change on the energy sector [1-3]. Despite the widespread belief of the scientists that climate change primarily affects energy consumption levels, it might not be the entire truth. At present, the energy consumption of buildings has been reported to account for $67 \%$ of the energy demand worldwide [4]. This has eventually attracted the attention of researchers to this vital issue in the construction sector and has turned reducing energy demands in the building sector as one 
of the important missions [5]. The energy consumption of buildings in the EU and the US contributed up to $40 \%$ of total global energy demand in 2019 [6], while according to the US Department of Energy report [7], 36\% of the total energy consumption in the US is the consumption of residential and commercial buildings. The existing literature (industry specific literature) indicates that researchers usually employ one of the below described approaches to address the issue.

The first approach, widely used in various studies, seeks to statistically analyze the relationship between major climate variables and energy demand variables such as: electricity consumption [8], heating and cooling energy demand [9-11], total energy consumption of buildings [12], fuel choice [13] or the cost of living [14], value of amenities [15] etc.

However, this method is limited to the study of the change in the energy demand and the socio-economic systems [16]. Limitations of the first approach have motivated the researchers to take another approach and to analyze the long-term changes by simulating building energy models. In this sense, by using TMY files the long-term impact of climate change in the form of a general year would be presented in the way that this year would be the representative of the whole historic period of baseline. The analysis of the climate change impact according TMY files based on historic baseline on the global energy consumption of residential buildings for heating and air conditioning purposes [17], assessing the energy consumption of buildings in the USA, Germany and China [18-22] by considering different climate scenarios are among important studies in this field.

This study evaluates and describes the global conditions of energy consumption in the building sector by reviewing the existing models, data, and predictions with the aim to extend the existing general knowledge of the impact of climate change on the energy consumption of buildings [23-25] through the use of a descriptive-analytical method.

\section{Climate Change}

The evidence of global warming indicates the impact of the greenhouse gases and the increase of average temperature of air on various aspects of urban life, such as health, water resources, energy, economy, politics, etc [26]. That is why, adaptation to the climate change can be considered as a vital challenge of the 21 st century to mitigate the adverse effects of global warming. Several international committees have attempted to use various methods for that purpose [27]. This area of the climate change impacts has been the subject matter of numerous studies because it is a vital issue for human life. Subsequently, the building sector has appeared to be extremely vulnerable to climate change influences such as global warming for instance [28]. Winter storms, flooding, droughts, storms as well as global warming that arise in the consequence of extreme weather patterns have posed a number of challenges for the building sector. Out of all of the aforementioned side effects, global warming seems to have the strongest implications for the future energy consumption patterns of building sector as IPCC (the Intergovernmental Panel on Climate Change) indicates its role in increasing energy demand and unreliability of energy supply [29].

While climate change and global warming are used to be considered mere hypotheses a decade ago, they are currently being recognized as the critical challenges to mankind 
globally [30]. Droughts in Australia, abnormal floods in the Asian countries such as Malaysia, rising sea levels, melting glaciers, intense seasonal heat waves in Europe and increased arctic ice melting are among the most visible signs of the climate change and global warming. Regardless of the foregoing, we all can also experience frequent extreme weather patterns like colder winters and warmer summers. The high frequency of heavy precipitation caused by the increasing atmospheric vapor, on the one hand, and rising the sea levels - up to $3.1 \mathrm{~mm}$ annually since 1993 - caused with the melting ice in Greenland and Antarctica, on the other hand, have turned the climate challenges into critical issues that require immediate action [31]. We may all remember the abrupt drops of temperature to extremely low values in the winter of 2003, after the extremely high summer temperatures [32] recorded in the so-called hottest European summer [33], when high temperatures at night caused nearly 15000 fatalities in France [34]. It is a clear-cut example of what will happen to mankind if the adaptation to the climate change will fail to be planned and implemented forthwith to counterbalance its adverse effects.

This study is based on the following definition of climate change: a climate shift caused by human activities that modify the natural greenhouse gas proportion in the lower atmosphere. This change might occur due to the technological progress. The types of climate change impact can be divided into three groups:

- Primary impact (e.g. on temperature, extreme climate phenomena, floods, extreme wind speeds)

- Secondary impact (e.g. changes in wildlife and nature)

- Tertiary impact (e.g., institutional, social, behavioral changes) [28]

According to the simulation-based analysis of the historical global climate data, global warming, monitored over the past 30 to 50 years, does not result from the natural forces like the tilting of the earth's axis alone. IPCC, thus, takes into account the possibilities of the combined effects of the climate change and human activities [35]. The increasing proportion of carbon dioxide in the atmosphere and its annually rising emission levels since the industrial revolution as shown in Figure 1 support this standing.

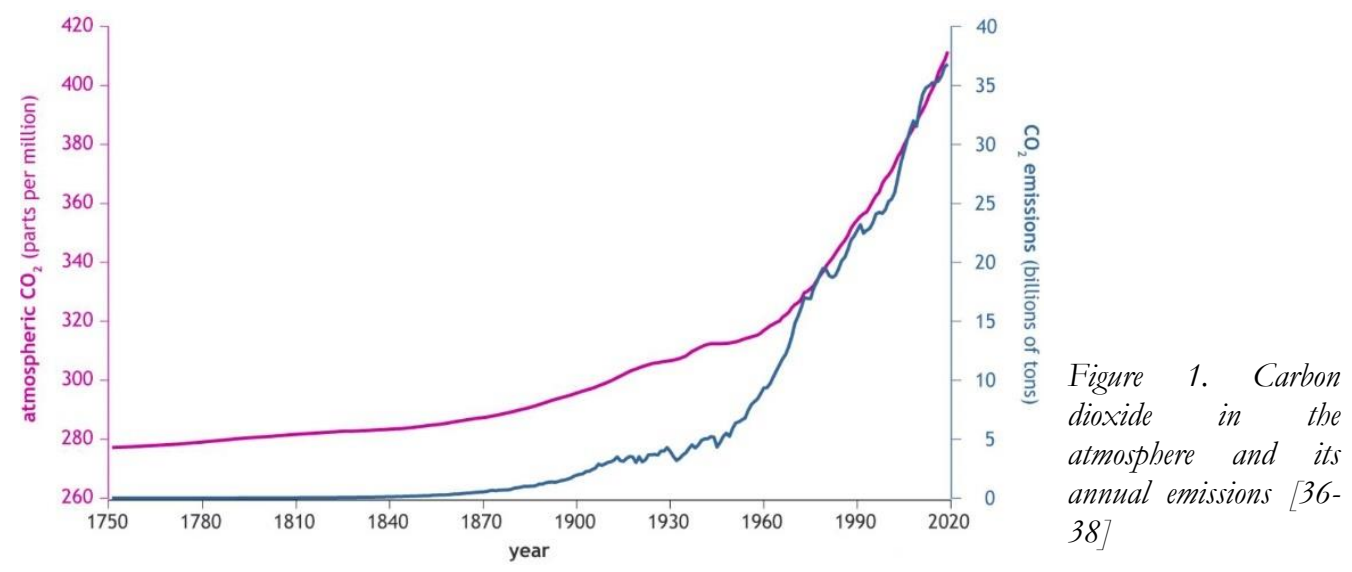

\section{Different Scenarios in Energy Trends}

Climate change forecast for a period of more than 100 years is used to be a mere 
scenario rather than an accurate forecast because several uncertain variables must be taken into account while interpreting the future climate parameters. These uncertainties include the climate system response to the weather changes, carbon emission levels and the socioeconomic progress. Atmosphere-ocean GCM Models (general circulation models) have been developed by IPCC for the purpose of climate forecasts. The GCM method [31] further anticipates the spatial resolution levels derived from atmospheric motion physics (5*5 latitude and longitude degrees) - in the UK, (HadCM3), USA (PCM), Canada (CGCM2) and Australia (CSIRP2) [31]. Emission scenarios developed by IPCC Work Group (WG) that describe potential energy trends are presented in Table. 1

Table 1. Energy trends scenarios based on the emission scenarios [31]

\begin{tabular}{|c|c|c|}
\hline \multicolumn{3}{|c|}{ Family No. Description } \\
\hline \multirow[t]{2}{*}{ A } & 1 & $\begin{array}{l}\text { Alternative energy systems such as non-fossil resources, fossil intensive or balanced } \\
\text { systems change as the result of the economic development and rapid population } \\
\text { increase }\end{array}$ \\
\hline & 2 & Economic growth while the population growth continues \\
\hline \multirow[t]{2}{*}{ B } & 3 & $\begin{array}{l}\text { Clean and resource-efficient technologies and service and information economy } \\
\text { become global trends as the result of the economic change caused with the population } \\
\text { peak in the mid-21st century }\end{array}$ \\
\hline & & $\begin{array}{l}\text { Achieving social, environmental and economic sustainability combined with the } \\
\text { economic development and moderate population growth through local solutions }\end{array}$ \\
\hline
\end{tabular}

A comprehensive overview of the climate change impact on the energy consumption of buildings shall underlie different climate scenarios that need to be taken into account. According to Clarke et al. [25], there are three possible climate scenarios;

- Fixed climate

- 4.5 climate

- 8.5 climate

While the first scenario seems unlikely, it still needs to be taken into account as a benchmark for other scenarios. This scenario assumes that there will not be any notable changes in temperatures (HDD as heating degree days and CDD as cooling degree days). The 4.5 climate scenario is based on the spatially detailed grid of temperature profiles originating from CESM (Community Earth System Model) and RPC 4.5 concentration pathway. The 8.5 climate scenario also relies on the same information from CESM and the RCP 8.5 concentration pathway [39], where CESM model was, in fact, developed in the 5th coupled model intercomparison project (CMIP5). The numbers (4.5 and 8.5) before names relate to the radiative forcing levels stabilization at $4.5 \mathrm{~W} / \mathrm{m}^{2}$ or $8.5 \mathrm{~W} / \mathrm{m}^{2}$ by 2100 . While these two scenarios differ only slightly, the first - fixed climate scenario is very different. Therefore, in fact we focus on only two climate scenario groups to be analyzed, both of which consider global population and per capita income to be the same. All the above-mentioned scenarios maintain that the increasing average global temperature is the parameter that indicates incremental warming. IPCC claims that this parameter has increased up to around $1{ }^{\circ} \mathrm{C}$ since the 18th century, which is illustrated in Figure 2. It will increase to $5.8^{\circ} \mathrm{C}$ and extreme weather phenomena will occur more frequently throughout 2100. 


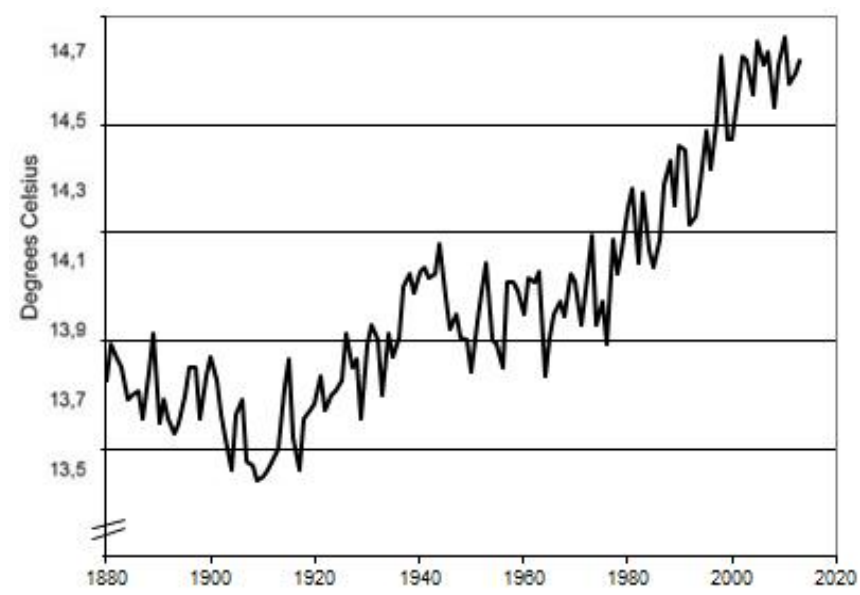

Figure 2. Global surface temperature since $1880[40,41]$

According to climate change forecasts in the UK, the average temperature is expected to rise from $0.1-0.3^{\circ} \mathrm{C}$ to around $0.3-0.5^{\circ} \mathrm{C}$ per decade for the low and high emission settings, respectively [42]. In this sense, summers are anticipated to become hotter and dryer, while winters will become wetter with $25 \%$ higher snowfall frequency by 2020 s and $45 \%$ by 2050s in the United Kingdom. It also has been estimated that in Asia average earth surface temperature would rise by $3{ }^{\circ} \mathrm{C}$ and $5^{\circ} \mathrm{C}$ in the 2050 s and the 2080 s, respectively. Moreover, average temperatures in Europe will rise by $2.4-5.4{ }^{\circ} \mathrm{C}$ over the next century due to high greenhouse gas emissions [43]. The highest carbon dioxide concentration is anticipated in the A2 scenario (Table. 1).

\section{Impact of the Climate Change on Energy Consumption of Buildings}

It has been proven that the environment type and climatic conditions affect several aspects of energy consumption of buildings[44]. This impact can be categorized into the following three groups:

- HVAC system (Heating, ventilation, and air conditioning)

- Heating and cooling demand

- Power peak demand [28]

\subsection{HVAC system}

Today, majority of the EU buildings are designed to use natural ventilation rather than any electric cooling appliances (e.g. air conditioning units) to mitigate their environmental impacts. Nevertheless, because the temperature in summers is more and more likely to reach extremely high values, we can observe a gradual growth of the HVACrelated energy consumption [45]. As a result of the extreme weather conditions, natural ventilation is often insufficient and consequently cooling demand in summer is on the rise. For instance, it has been predicted that by 2080, the energy demand for air conditioning needs in buildings in July and August will rise by 30\% in Athens [46]. Moreover, we can observe that in the UK around $40 \%$ of large buildings are provided with air conditioning devices as compared to $10 \%$ in 1994 [47], while most buildings, constructed before 1990, were designed to be naturally ventilated [48]. 
Increasing extreme and average temperatures will result in uncomfortable and expensive buildings in terms of their cooling and heating, and in consequence, into an urgent need of retrofitting mechanical systems such as ventilation, for instance. Better HVAC equipment is now needed to mitigate the effects of increased humidity and heat gain of outdoor air in summers resulting from higher outdoor wet and dry bulb temperature in order to achieve acceptable conditions of comfortable living. On the other hand, it has been proven that such conditions heavily depend on the influence of the temperature rising and that there is a strong negative correlation between the efficiency of HVAC systems and wet/dry bulb temperatures (WBT and DBT). This means that at high WBT/DBT values, the efficiency of HVAC systems decreases [49]. Therefore, HVAC systems in buildings are likely to increase their share in the energy consumption in warmer areas, where WBT/ DBT is increasing.

\subsection{Heating and cooling demand}

The most visible impact of the climate change on the energy consumption of buildings is the increased consumption rate of the cooling and heating energy. This can be seen as the result of the growing need for appropriate thermal comfort in buildings during hot summers and cold winters [50, 51]. Studies have shown that the trend of the temperature increasing over recent years in the global scale has caused further discomfort in summers and less discomfort in winters [52]. changes in heating and cooling energy demands are considered the consequence of changes in degree-days [53]. The lastmentioned variable is highly affected by the geographical location of the analysis area. Possible types of impacts of the climate change on cooling and heating loads, being the key parameters in determining the energy consumption of buildings, have been widely discussed in several studies [54-56], many of which have been based on the degree-day approach $[1,10]$.

Using computational methods, the majority of aforementioned studies predict a sharp decrease in the heating energy demand and a considerable increase in the cooling demand in the building sector $[57,58]$. The studies have observed that future decrease in the heating energy demand will outweigh the decrease rate of heating degree-days, while possible cooling energy demand is anticipated to increase considerably. According to cooling degree-days rate, the cooling energy demand is predicted to rise by $2100 \%$ in the period from 1975 to 2085 [59]. This validates the results of the previous studies that have indicated a decreased demand for heating and increased demand for cooling in the building sector. That is why, higher energy demand is expected in summers and springs in hot countries (e.g. Mexico), whereas cold countries (e.g. Canada, Norway) are predicted to consume less energy in winters. In mild countries (e.g. Italy) the additional cooling energy demand during summers is balanced with the reduction of the heating energy demand in winter and spring $[10,11,54]$. Table. 2 below presents the summary of studies referred to in this statement. 
Table 2. Researchers' conclusions concerning the cooling and heating energy demands in buildings

\begin{tabular}{|c|c|c|c|}
\hline \multirow{2}{*}{ Study area } & \multicolumn{2}{|c|}{ Building energy load } & \multirow{2}{*}{$\begin{array}{c}\text { Change in temperature }{ }^{\circ} \mathrm{C} \\
\text { (date of the change) }\end{array}$} \\
\hline & Cooling load & Heating load & \\
\hline \multirow{6}{*}{ the USA $[11,54,60]$} & $+15 \%$ & $-16 \%$ & $1(2010)$ \\
\hline & $+53.9 \%$ & $-29-35 \%$ & $1(2003)$ \\
\hline & $+9.4-15 \%$ & $-5-24 \%$ & 3.9 or $1(2030)$ \\
\hline & $+17 \%$ & $-12 \%$ & $1.7(2020)$ \\
\hline & $+36 \%$ & $-22 \%$ & $3.4(2050)$ \\
\hline & $+53 \%$ & $-33 \%$ & $5.3(2080)$ \\
\hline Switzerland [53] & $+44-58 \%$ & & $4.4(1901-2003)$ \\
\hline Italy & $+1.17 \%$ & $-0.21 \%$ & 1 (summers) \\
\hline
\end{tabular}

\subsection{Power peak demand}

The majority of the studies related to the climate change impact on power peak demand in buildings indicate a sharp fall in the heating energy demand and a considerable increase in the cooling energy demand in recent years [61]. Some scholars were of the opinion that the increasing cooling demand would be balanced with the decreased heating demand, while others anticipated that the cooling energy demand might entirely dominate the power sector [19]. However, it should be noted that the climate change impact on the energy consumption of buildings is also influenced by other factors such as the climate change scenarios and building types. Huang team [60] has also predicted a sharp decline in the energy demand in the colder areas in the future. Although lighting and plug loads seem to be the primary sources of power consumption in the buildings, it has been found that the cooling loads represent a major part of power consumption, which is expected to rise even more in the next 100 years by over $50 \%$ [28]. Therefore, it is concluded that the impact of climate change on the electricity consumption in the building sector will result in the rise of energy consumption due to the increased demand for cooling. However, the increased consumption rate varies depending on the building type and its size, which determine the sensitivity of a given building to the climate change.

\section{Results and Discussion}

By applying the climate scenarios (Table. 2), we would be able to decrease the number of variables and analyze each scenario in accordance with the conditions of the given group. The first scenario assumes the climate as a fixed variable. However, there is a wide range of uncertainties that should be taken into account that with improving adaptability we could manage to cope with them [62], including possible fundamental socio-economic trends such as the population and the global average income (per capita income) that are expected to grow and the building technology that is expected to be improved. These variables follow the pathway introduced by Fricko [63], which anticipates that the global population will peak in 2070 and decline by the end of the century. This peak is assumed to take place mainly in the developing countries, while the population in industrialized regions (developed countries) is expected to remain nearly unchanged. Considering the likely substantial economic growth, per capita income in developing countries might eventually converge with that generated in the developing countries. It 
should be noted that substantial risks for a collapse of civilization, also in terms of global population peak, exist well before 2070, due to over-exploiting of natural resources [64]. On the one hand, as the building technologies are expected to undergo significant improvements (e.g. enhancement in the building shell efficiency), heating and cooling demands are assumed to decrease as a result. On the other hand, innovative solutions in the cooling and heating equipment itself will translate into decreased cooling and heating systems demands.

It can be observed that energy consumption trends in buildings are focusing on the cooling and heating energy demands. More specifically, according to Clarke [25], the number of heating and cooling degree-days in 2010 indicates that despite notable difference in cold and hot regions, the cumulative numbers of these variables are nearly the same, which is illustrated in Figure. 3

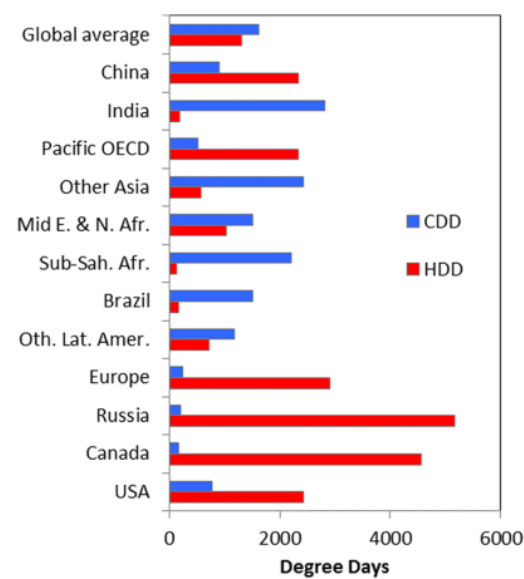

Figure 3. The number of degree-days in different regions in 2010 [25]

Although scenarios differently predict the heating and cooling degree, they all agree on the global warming phenomenon, a sharp increase in the cooling energy demand (cooling degree days), and a drop in the heating energy demand (heating degree days) within the next $80-90$ years. Figure. 4 shows the data studied in all parts of the world.
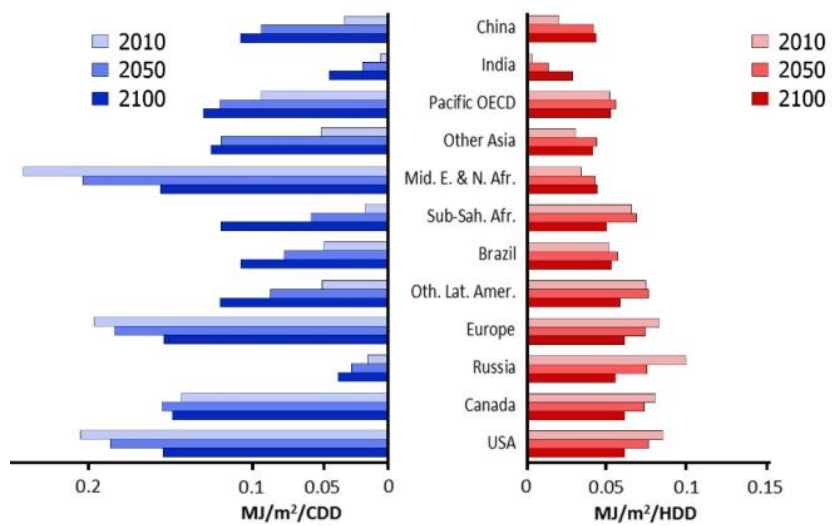

Figure 4. The number of cooling and heating degree days in different regions in 2010, 2050, and 2100, based on [25] 
By analyzing the entire data set from different world regions, global trends in the energy consumption of buildings can be defined based on the cooling and heating degree-days. Figure. 5 illustrates that the CDD numbers are clearly increasing, while the HDD number shows a slight rise and then a sharp drop. This means that at some point in the future (near 2070), cooling energy loads would outweigh the heating energy demands in the building sector, and since then, the difference between these variables would probably rise quite fast.

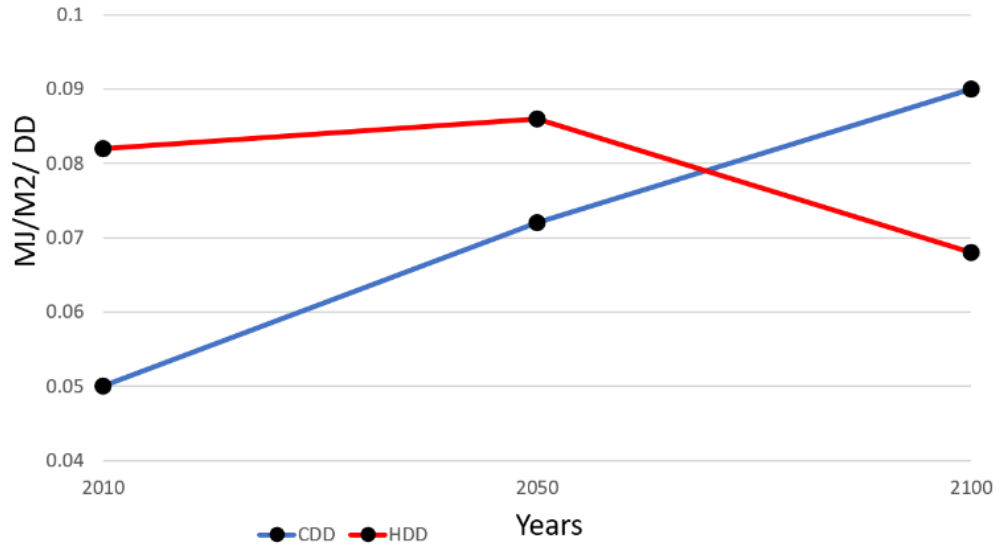

Figure 5. Global trends of cooling and heating degree days in 2010, 2050, and 2100, based on [25]

\section{Conclusion}

This paper seeks to present an accurate overview of the climate change impact as a severe consequence of economic, industrial and similar changes such as the technological progress and the population growth on the energy consumption of buildings. Having analyzed the current state of knowledge on the topic, presented in the industry specific literature, this study confirms that global warming is the most severe consequence of the climate change that we are likely to face in the future. It further moves to study possible energy trends and the climate change scenarios. Assuming the presented scenarios as the input data and using the existing methods of analysis, respective results have been obtained accounting for all the possible aspects of energy consumption in buildings influenced by the climate change. Cooling and heating energy demand, which represents the largest share in the energy consumption in the building sector, has been confirmed as the main factor clearly showing the climate change impact on the energy consumption of buildings. Using the degree-days method, the authors have interpreted the results of studies in this field to define the global trends in the energy consumption in the building sector resulting from the influence of the climate change. The study carried out by the authors has come to the conclusion that the cooling energy demand is increasing, while the energy demand for heating in buildings will sharply decrease. This means that the issue of cooling needs to be urgently addressed to assure comfortable temperatures in buildings that in the future will be exposed to higher and higher ambient temperatures.

Consequently, by comparing the data and predicted values of HDD/CDD in different 
regions, it is estimated that colder regions such as Russia and Canada, for instance, will consume less energy as cooling demand in those regions is negligible, whereas the overall energy consumption in the building sector in these regions will decrease significantly. On the other hand, moderate and hot climate areas will show higher cooling demand and thus, the building sector in those areas will consume more energy. In the global scale, the declined heating energy demand will at a certain point in future balance with the increased cooling demand (around 2070), and thereafter we can expect a sharp increase in the cooling loads that will translate into overall higher energy consumption in the building sector.

\section{Acknowledgment}

This paper is a part of corresponding author's $\mathrm{PhD}$ thesis in Poznan University of Technology which is funded within the framework of the research project entitled "Mapping of architectural space, history, theory, practice, and modernity." (Grant number: 0112/SBAD/0171)

\section{References}

1. Amato, A.D., et al., Regional Energy Demand Responses To Climate Change: Methodology And Application To The Commonwealth Of Massachusetts. Climatic Change, 2005. 71(1): p. 175-201.

2. Bazazzadeh, H., et al., Promoting Sustainable Development of Cultural Assets by Improving Users' Perception through Space Configuration; Case Study: The Industrial Heritage Site. Sustainability, 2020. 12(12): p. 5109.

3. Mahdavinejad, M., M. Didehban, and H. Bazazzadeh, Contemporary architectural heritage and industrial identity in bistoric districts, case study Dezful. Journal of Studies on Iranian Islamic Cities, 2016. 6(22): p. 10.

4. Madlener, R. and Y. Sunak, Impacts of urbanization on urban structures and energy demand: What can we learn for urban energy planning and urbanization management? Sustainable Cities and Society, 2011. 1(1): p. 45-53.

5. Nik, V.M. and A. Sasic Kalagasidis, Impact study of the climate change on the energy performance of the building stock in Stockholm considering four climate uncertainties. Building and Environment, 2013. 60: p. 291-304.

6. Cao, X., X. Dai, and J. Liu, Building energy-consumption status worldwide and the state-of-the-art technologies for zeroenergy buildings during the past decade. Energy and Buildings, 2016. 128: p. 198-213.

7. EIA, Monthly energy review. 2019, Washington DC, USA: Adminstration U.S. Energy Information.

8. Sailor, D.J., Relating residential and commercial sector electricity loads to climate-evaluating state level sensitivities and vulnerabilities. Energy, 2001. 26(7): p. 645-657.

9. Sailor, D.J. and A.A. Pavlova, Air conditioning market saturation and long-term response of residential cooling energy demand to climate change. Energy, 2003. 28(9): p. 941-951.

10. Cartalis, C., et al., Modifications in energy demand in urban areas as a result of climate changes: an assessment for the southeast Mediterranean region. Energy Conversion and Management, 2001. 42(14): p. 1647-1656.

11. Rosenthal, D.H., H.K. Gruenspecht, and E.A. Moran, Effects of global warming on energy use for space beating and cooling in the United States. The Energy Journal, 1995. 16(2).

12. Wan, K.K.W., et al., Future trends of building beating and cooling loads and energy consumption in different climates. Building and Environment, 2011. 46(1): p. 223-234.

13. Mansur, E.T., R. Mendelsohn, and W. Morrison, Climate change adaptation: A study of fuel choice and consumption in the US energy sector. Journal of Environmental Economics and Management, 2008. 55(2): p. 175193.

14. Maddison, D., The amenity value of the climate: the household production function approach. Resource and Energy Economics, 2003. 25(2): p. 155-175.

15. Albouy, D., et al., Climate amenities, climate change, and American quality of life. Journal of the Association of Environmental and Resource Economists, 2016. 3(1): p. 205-246.

16. Attarian, K. and B. Safar Ali Najar, Vernacular and bistoric underground urban facilities and sustainability of cities case study. Journal of Cultural Heritage Management and Sustainable Development, 2019. 9(1): p. 2 23. 
17. Isaac, M. and D.P. van Vuuren, Modeling global residential sector energy demand for heating and air conditioning in the context of climate change. Energy Policy, 2009. 37(2): p. 507-521.

18. Zhou, Y., J. Eom, and L. Clarke, The effect of global climate change, population distribution, and climate mitigation on building energy use in the U.S. and China. Climatic Change, 2013. 119(3): p. 979-992.

19. Hadley, S.W., et al., Responses of energy use to climate change: A climate modeling study. Geophysical Research Letters, 2006. 33(17).

20. Edmonds, J., et al., Stabilization of CO2 in a B2 world: insights on the roles of carbon capture and disposal, hydrogen, and transportation technologies. Energy Economics, 2004. 26(4): p. 517-537.

21. Olonscheck, M., A. Holsten, and J.P. Kropp, Heating and cooling energy demand and related emissions of the German residential building stock under climate change. Energy Policy, 2011. 39(9): p. 4795-4806.

22. Scott, M.J., J.A. Dirks, and K.A. Cort, The value of energy efficiency programs for US residential and commercial buildings in a warmer world. Mitigation and Adaptation Strategies for Global Change, 2008. 13(4): p. 307-339.

23. Eom, J., et al., Exploring the future role of Asia utilizing a Scenario Matrix Architecture and Shared Socio-economic Pathways. Energy Economics, 2012. 34: p. S325-S338.

24. Eom, J., et al., China's building energy demand: Long-term implications from a detailed assessment. Energy, 2012. 46(1): p. 405-419.

25. Clarke, L., et al., Effects of long-term climate change on global building energy expenditures. Energy Economics, 2018. 72: p. 667-677.

26. Bazazzadeh, H., et al., Requirements for comprehensive management of industrial heritage sites and landscapes, in International Conference on Conservation of 20th Century Heritage from Architecture to Landscape, S. Fadaei nejad bahramjerdi, Editor. 2018, Univeristy of Tehran Tehran, Iran.

27. Mancini, F. and G. Lo Basso, How Climate Change Affects the Building Energy Consumptions Due to Cooling, Heating, and Electricity Demands of Italian Residential Sector. Energies, 2020. 13(2): p. 410.

28. Yau, Y.H. and S. Hasbi, A review of climate change impacts on commercial buildings and their technical services in the tropics. Renewable and Sustainable Energy Reviews, 2013. 18: p. 430-441.

29. IPCC, Climate Change 2001: Synthesis Report: Third Assessment Report of the Intergovernmental Panel on Climate Change. 2002: Cambridge University Press.

30. Bazazzade, H. and M. Ghomeshi, The black Bridge of Ahwa: TICCIH Bulletin, 2018. 80.

31. IPCC, Climate Change 2007 - The Physical Science Basis: Working Group I Contribution to the Fourth Assessment Report of the IPCC. 2007: Cambridge University Press.

32. Bader, S., Extreme summer heat in the climatic year 2003. 2004, Zurich, Switzerland: Federal office of meteorology and climatology.

33. Luterbacher, J., et al., European Seasonal and Annual Temperature Variability, Trends, and Extremes Since 1500. Science, 2004. 303(5663): p. 1499-1503.

34. Schär, C., et al., The role of increasing temperature variability in European summer heatwaves. Nature, 2004. 427(6972): p. 332-336.

35. Obasi, G.O.P. and E. Dowdeswell, Climate Change 1995: IPCC Second Assessment: A Report of the Intergovernmental Panel on Climate Change Ipcc. 1998: Diane Publishing Company.

36. Adminstration, N.O.a.A. Trends in atmospheric carbon dioxide. 2020 Dec. 27. 2020]; Available from: www.esrl.noaa.gov.

37. Ritchie, H. and M. Roser. Annual carbon dioxide emissions. 2018 Dec. 27.2020]; Available from: https://ourworldindata.org/co2-emissions.

38. Lindesy, R. Climate change; Atmospheric carbon dioxide. 2020 Dec. 27.2020]; Available from: https://www.climate.gov/news-features/understandingclimate/climatechangeatmosphericcarbondioxide.

39. Meehl, G.A., et al., Climate Change Projections for the Twenty-First Century and Climate Change Commitment in the CCSM3. Journal of Climate, 2016. 19(11): p. 20.

40. Mashhoodi, B., The Spatial Dimension of Household Energy Consumption. A+BE Architecture and the Built Environment. 2019, Delft, Netherlands: TU Delft.

41. Larsen, J. Eco-economy indicators; Global temperature. 2014 Dec. 27.2020]; Available from: http://www.earthpolicy.org/indicators/C51.

42. Hulme, M., et al., Climate Change Scenarios for the United Kingdom: The UKCIP02 Scientific Report. 2002, Tyndall Centre for Climate Change Research, School of Environmental Sciences, University of East Anglia: Norwich, U.K. 
43. Met, Uncertainity, risk and dangerous climate change. 2004, The Hadley Centre: United Kingdom.

44. Bazazzadeh, H., Truth of sincerity and authenticity or lie of reconstruction; whom do the visitors of cultural heritage trust?, in International conference of defining the architectural space. 2020: Cracow, Poland.

45. Pérez-Lombard, L., J. Ortiz, and C. Pout, A review on buildings energy consumption information. Energy and Buildings, 2008. 40(3): p. 394-398.

46. Giannakopoulos, C. and B.E. Psiloglou, Trends in energy load demand for Athens, Greece: weather and non-weather related factors. Climate research, 2006. 31.

47. CTG005, T.G., airconditioning: maximisingcomfort, minimising energy consumption. 2007, CarbonTrust: London.

48. ODPM, age of commercial and industrial stock: local authority: level 2004 England and Wales. 2005, London, England: Office of Deputy Prime Minister.

49. Delfani, S., M. Karami, and H. Pasdarshahri, The effects of climate change on energy consumption of cooling systems in Tehran. Energy and Buildings, 2010. 42(10): p. 1952-1957.

50. Lam, J.C., et al., Building energy efficiency in different climates. Energy Conversion and Management, 2008. 49(8): p. 2354-2366.

51. Lam, J.C., et al., Weather data analysis and design implications for different climatic zones in China. Building and Environment, 2005. 40(2): p. 277-296.

52. Humphreys, M., Outdoor temperatures and comfort indoors. Batiment International, Building Research and Practice, 1978. 6(2): p. 92-92.

53. Frank, T., Climate change impacts on building heating and cooling energy demand in Switzerland. Energy and Buildings, 2005. 37(11): p. 1175-1185.

54. Belzer, D.B., M.J. Scott, and R.D. Sands, Climate Change Impacts on U.S. Commercial Building Energy Consumption: An Analysis Using Sample Survey Data. Energy Sources, 1996. 18(2): p. 177-201.

55. Considine, T.J., The impacts of weather variations on energy demand and carbon emissions. Resource and Energy Economics, 2000. 22(4): p. 295-314.

56. Camilleri, M., R. Jaques, and N. Isaacs, Impacts of climate change on building performance in New Zealand. Building Research \& Information, 2001. 29(6): p. 440-450.

57. Aguiar, R., M. Oliveira, and H. Gonccedilalves, Climate change impacts on the thermal performance of Portuguese buildings. Results of the SLAM study. Building Services Engineering Research and Technology, 2002. 23(4): p. 223-231.

58. Christenson, M., H. Manz, and D. Gyalistras, Climate warming impact on degree-days and building energy demand in Switzerland. Energy Conversion and Management, 2006. 47(6): p. 671-686.

59. Benestad, R.E., Cooling degree days and anticipation in Europe, in Analysis for the CELECT project. 2008, Met institute.

60. Huang, W.Z., M. Zaheeruddin, and S.H. Cho, Dynamic simulation of energy management control functions for HV AC systems in buildings. Energy Conversion and Management, 2006. 47(7): p. 926-943.

61. Rong, F. and S. Smith, Climate Change and the Long-Term Evolution of the U.S. Buildings Sector. 2007, Richland, USA: Pacific Northwest National Laboratory.

62. Bazazzade, H., et al., The Importance of Flexibility in Adaptive Reuse of Industrial Heritage: Learning from Iranian Cases. International Journal of Conservation Science, 2021. 12(1).

63. Fricko, O., et al., The marker quantification of the Shared Socioeconomic Pathway 2: A middle-of-the-road scenario for the 21st century. Global Environmental Change, 2017. 42: p. 251-267.

64. Bologna, M. and G. Aquino, Deforestation and world population sustainability: a quantitative analysis. Scientific Reports, 2020. 10(1): p. 7631. 